be congratulated on having, in one small volume, covered the history of compasses from about A.D. 120 to 1952 in a style which is both interesting and instructive. In addition they also give in simple language a brief idea of how each type of compass works, together with its merits and demerits and its particular advantages over other types under certain conditions. To the best of the reviewer's belief there is no other work in existence which gives all this information in one volume.

The first chapter deals with the early history of compasses, for which Captain Hitchins rightly gives credit to Commander May, who is certainly one of the best-informed authorities on the subject today. Then follow chapters on the Magnetism of the Earth and Errors of the Magnetic Compass in Ships. These chapters are particularly useful as they cover the subject in a simple way, easily understood by anyone with a most elementary knowledge of magnetism. The succeeding chapters deal with the development of the magnetic compass and gyro-compass, compasses for use in aircraft, inductor compasses and many other types including sun compasses. The variety of types and combinations of types of compasses in use for different purposes is both interesting and intriguing. The final chapter describes the sky compass which makes use of polarized light from the Sun and which is still in the development stage.

Your reviewer would recommend this book to all with an interest in ship and aircraft navigation and in particular to the young cadet or apprentice commencing his sea-going career. It should make a very useful and interesting introduction to what is generally considered a very difficult subject not to be tackled until the last possible moment when an approaching examination makes it necessary. In addition, since elementary principles of navigation have been recently introduced into the curriculum of schools of this country, it should make a valuable addition to school libraries.

W. D.

\title{
ERRATUM
}

\section{The Treatment of Navigational Errors}

The last term in the formula printed on line 28, page 104 of the April number should read $\left(\right.$ tilt $\left.^{\circ}\right)$, not $\left(\text { tilt }^{\circ}\right)^{2}$. 